\title{
La voz y el silencio: la hegemonía en la representación de Cleón en las Historiae de Tucídides ${ }^{1}$
}

\author{
The voice and the silence: hegemonia in Cleon's representation in Thucydides' Historiae \\ Mariana Franco San Román \\ Universidad de Buenos Aires, Argentina \\ mariana.franco@filo.uba.ar \\ (iD https://orcid.org/0000-0003-4321-1505
}

\section{Resumen:}

Dada la ubicuidad de la guerra en la realidad helénica antigua en general y, en particular, en la formación del líder político, la figura de Cleón en las Historiae descolla como inusual. El objetivo del presente artículo es identificar y analizar los recursos a los que recurre el enunciador-historiador para representar el êthos del político en términos de su participación militar. Nuestra hipótesis es que su caracterización como "el más persuasivo" (Tucídides 3.36.6, 4.21.3) implicaría una actitud irónica. En este sentido, su capacidad oratoria estaría restringida al ámbito de la pólis y no parece tener palabras para sus soldados en el campo de batalla cuando se enfrenta con los espartanos en Esfacteria y, mucho menos, en la preanunciada derrota de Anfípolis. En este sentido, la descripción de Cléon es eminentemente política y su participación militar es menoscabada por el enunciador-historiador, en contraste con las de Demóstenes y Brásidas.

Palabras Clave: Cleón, Tucídides, Guerra, Discurso, Êthos.

\section{ABSTRACT:}

Given the ubiquity of war in the Ancient Hellenic reality in general and, in particular, in the training of political leaders, the Thucydidean Cleon stands out as unusual. This article aims to identify and analyze the resources with which the historian represents the politician's êthos in terms of his military participation. The hypothesis is that his characterization as "the most persuasive" (Thucydides 3.36.6, 4.21.3) entails an ironic attitude towards him. In a sense, his oratorical ability seems restricted to the pólis: he does not look like he has any words to offer to his soldiers on the battlefield when he faces the Spartans at Sphacteria and, much less, at the foretold defeat in Amphipolis. On this matter, Cleon's description is eminently political and his military participation is diminished by the historian, in contrast to those of Demosthenes and Brasidas.

KeYwords: Cleon, Thucydides, War, Discourse, Êthos . 
Si bien para un escritor como Aristófanes (Caballeros 801-9) la guerra puede ser vista como una de las formas de perturbación de la pólis, lo cierto es que, dada su ubicuidad en la realidad helénica antigua, ocupa un lugar predominante en la configuración del ciudadano. Al respecto, Mossé sostiene: “...désormais le citoyen et le soldat ne font qu'un et le citoyen-soldat exerce sa souveraineté aussi bien au sein de l'Assemblée des citoyens en temps de paix, qu 'à 1 'intérieur du camp en temps de guerre. De ce fait, le chef militaire ne se distingue pas du chef politique" (1999, p. 292). Esta afirmación puede ser puesta en entredicho si tenemos en cuenta la figura de Cleón, tal como Tucídides lo caracteriza tanto en el episodio de Pilos como en el de la Campaña del Norte.

El objetivo del presente artículo es identificar y analizar los recursos a los que recurre el enunciadorhistoriador para representar al hijo de Cleeneto en términos de su participación militar o hegemonía. Por un lado, las figuras de Demóstenes y de Brásidas son piezas clave en dicha representación en términos de oposición y en ambos casos operan tres elementos: el temor, el plan y la experiencia. Por el otro, nos centraremos en las intervenciones de Cleón y veremos el lugar que el discurso ocupa en ellas, dado su carácter de pithanótatos tồ démou (Tucídides 3.36.6, 4.21.3). ${ }^{2}$ La ausencia de discursos adjudicados al político en las campañas militares en las que participó no puede ser pasada por alto: el campo de acción de su palabra es la Asamblea y no el campo de batalla. Simultáneamente, los discursos de Brásidas resaltan por su cantidad (tres orationes rectae y tres en estilo indirecto) y contrastan con un breve discurso en estilo indirecto adjudicado a Cleón hacia el final del episodio, que tendrá unas características muy específicas. En las arengas en particular veremos que el enunciador-historiador busca construirle al espartano un êthos complejo de general competente a partir de dos éthe, el didáctico y el heroico. ${ }^{3}$ Esto no hará más que enfatizar la incompetencia de Cleón en dicho ámbito y permitirá explicar su eventual derrota y muerte. En este sentido, Cleón es el anti-êthos de Brásidas. ${ }^{4}$ Simultáneamente, este procedimiento se asociará a otro, la descalificación del adversario, en este caso como general inepto y un cobarde. ${ }^{5}$ Esto supone pensar el texto tucidídeo inmerso en una polémica sobre cómo deben ser los líderes.

\section{La Campaña de Pilos: la estrategia de Demóstenes}

La primera participación militar de Cleón en las Historiae es en la Campaña de Pilos como comandante. Lo cierto es que esta no podría haber ocurrido si el pedido espartano de treguas no se hubiera rechazado a instancia suya. Tucídides deja en claro, cuando dé cuenta de la Paz de Nicias, que los atenienses dejaron pasar una buena ocasión para firmar una tregua (Tucídides 5.14.1, 5.15.2) y se entiende que la postura del hijo de Cleeneto implica una actitud pro-bélica y expansionista a partir de los reclamos que hace ante los lacedemonios. ${ }^{6}$

Tucídides nos narra que, ante la reanudación de las hostilidades y la continuación del bloqueo de la isla por el rechazo de la oferta de paz, el hijo de Cleeneto critica a los generales por cómo estaban llevando a cabo la campaña; el ataque, dirigido en particular a Nicias, tiene como resultado que Cleón acepta el mando que el strategós le ofreció (Tucídides 4.27-28). ${ }^{7}$ Tras elegir a Demóstenes como colega, promete la toma de la isla en veinte días (Tucídides 4.29) sin llevarse ningún hoplita ateniense, algo que terminará eventualmente por cumplirse (Tucídides 4.39). ${ }^{8}$

La crítica en general ha considerado que el strategós y el político estaban en connivencia para llevar a cabo esta campaña, ${ }^{9}$ lo que se podría ver como una expresión de esa disociación de funciones entre generales y oradores, ${ }^{10}$ entendidos estos últimos como los "expertos indispensables" a la hora de aconsejar en la toma de decisiones y formados particularmente para ello mientras los primeros se encontraban fuera de la ciudad cumpliendo con sus tareas militares. ${ }^{11}$ Según Ober (1989) la tendencia a la especialización podría 
ser atribuida no solo a las exigencias de la guerra, sino también a la posibilidad de que Pericles quizás hubiera desalentado a sus potenciales rivales (p. 91). Ante esta postura, Hansen (1999) considera a Cleón, al igual que a otras figuras que lo antecedieron, como un político que reunió ambos tipos de liderazgo -el militar y el político- y ubica la disociación de funciones recién después de la restauración democrática de 403/2 a.n.e. (p. 269). De un modo similar, Rhodes (2016) sostiene que hasta el tercer cuarto del siglo IV a.n.e. no encontramos administradores expertos. Sin embargo, matiza esta afirmación al reconocer que esto no implica necesariamente que los políticos no tuvieran alguna expertise en particular (p. 257). ${ }^{12}$

A pesar de esta experiencia militar, lo cierto es que el enunciador-historiador focaliza su narración en Demóstenes. ${ }^{13}$ Para ello, Tucídides recurre a tres estrategias para realzar su participación, lo que tiene por efecto un borramiento del liderazgo cleoniano en materia militar.

En primer lugar, está la negación inicial del mando y la adjudicación de cierta aprehensión.

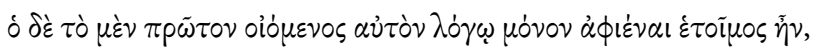

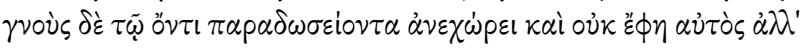

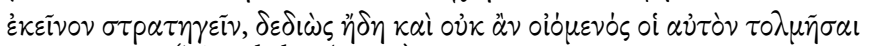

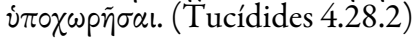
Este [Cleón] en un primer momento creyendo que aquel [Nicias] [le] dejaba [el mando] solo de palabra estaba dispuesto [a aceptarlo], pero cuando supo que estaba presto a entregarlo en verdad se echó atrás y dijo que él no era general, sino aquel; para entonces tuvo miedo y no habría creído que aquel [Nicias] hubiera tenido el valor a ceder[lo].

El verbo deidein da cuenta justamente de una aprehensión y duda ante la acción razonada ( $\gamma$ voìs) (Huart, 1968, pp. 336-337). ${ }^{14}$ En tal sentido, supone una decisión de tipo práctica, en este caso la aceptación del mando que Nicias le cede. Resulta interesante que es a instancias de la multitud (ókblos) que termina consintiendo y Tucídides transmite un discurso en estilo indirecto en el que Cleón niega temerle a los lacedemonios ( $\phi \circ \beta \varepsilon \tilde{\sigma} \sigma \alpha \mathrm{l}$ है $\phi \eta \Lambda \alpha \kappa \varepsilon \delta \alpha \mu o v i o v \varsigma) .{ }^{15}$ Además, él mismo es quien había presentado el asunto en términos de andreía:

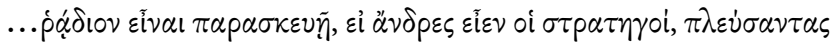

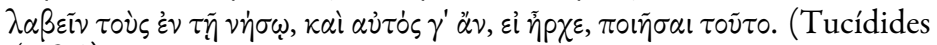 4.28.1) \\ ...[dijo] que era fácil con esas fuerzas, si los strategoi fueran hombres, navegar para tomar a los de la isla y que él mismo habría hecho esto si hubiera tenido el mando.}

La andreía tiene como formante etimológico a $\alpha \dot{\nu} \eta \dot{\rho}$, por lo que el reproche cleoniano parece estar fundado en una apreciación de este valor: lo que significa "to be a man begins as an observable act of facing death on the battlefield...” (Bassi, 2003, pp. 25-26). ${ }^{16}$ De hecho, la "escena prototípica” de las manifestaciones del coraje y la valentía es la guerra pues es la que ofrece un peligro inmediato al que puede enfrentarse el hombre. ${ }^{17}$ Es posible afirmar, entonces, que todo este episodio se puede resumir en términos de quién tiene el coraje de hacerse cargo de la continuación de la expedición y, a los ojos del enunciador-historiador, Cleón no es una opción.

La segunda estrategia a la que recurre es dar cuenta de cuál es el plan y adjudicárselo a Demóstenes. ${ }^{18}$ Sabemos que el hijo de Cleeneto elige al strategós como compañero (Tucídides 4.29.1) porque $\tau \dot{\text { cò }} \delta \dot{\varepsilon}$

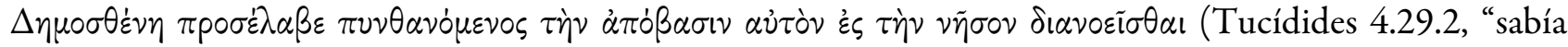
que Demóstenes pensaba desembarcar él mismo en la isla”). ${ }^{19}$ En Tucídides 4.31-32 se describe el

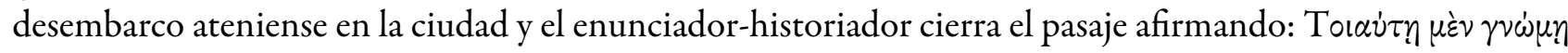

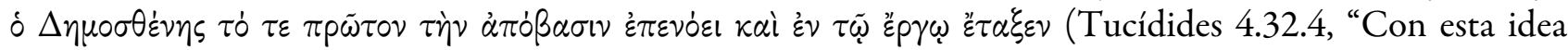
Demóstenes en primer lugar planeaba el desembarco y lo dispuso en la práctica"). Los hechos, entonces,

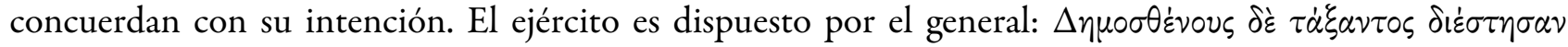

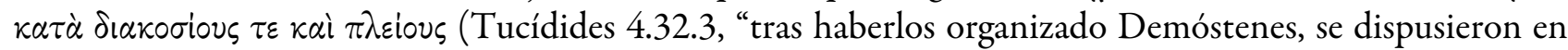
[grupos] de doscientos [hombres] y también más...”). Resalta en ambos pasajes el uso del verbo tássein: es el strategós quien ordena o dispone, no Cleón. 
Esta aseveración se ve confirmada si tenemos en cuenta que el político es apenas mencionado. Participa en todas situaciones diplomáticas, no bélicas en sí. El hijo de Alcístenes es quien teme el peligro inmanente

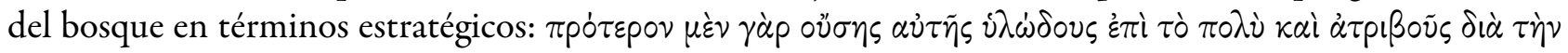

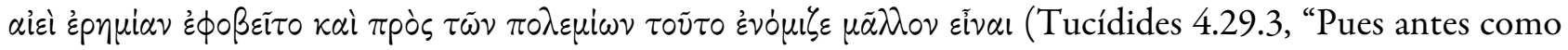
gran parte de esta [Esfacteria] era boscosa y no tenía caminos por haber estado siempre deshabitada, temía y consideraba que esto era mejor para los enemigos"). Y no en vano Tucídides afirma que Demóstenes $\tau \dot{\eta} \nu$

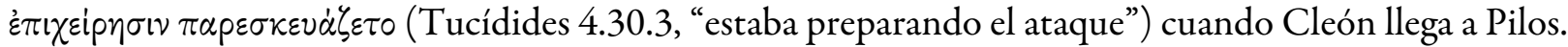

Esto nos lleva al tercer elemento, la experiencia, que juega un papel clave en todo el episodio. El enunciadorhistoriador resalta que la aprehensión del general radica en su experiencia fallida en Etolia (Tucídides 3.97-98). ${ }^{20}$ En aquel entonces, la expedición que había encabezado había fallado porque los etolios habían aprovechado la cobertura que ofrecía el bosque y el uso de tropas ligeras. ${ }^{21}$ Estos dos elementos volverán a aparecer en Pilos: la destrucción del bosque le permitirá observar cuántos son los lacedemonios (Tucídides 4.30.3) y preparar el ataque con el mismo tipo de fuerzas. A esto cabe agregar que la maniobra a la que apela es la misma que había utilizado con los ampraciotas (Tucídides 3.112.3) al sorprender a sus enemigos antes del alba. ${ }^{22}$

Estos tres puntos -el temor, el plan y la experiencia-, veremos, reaparecen en la campaña de Anfípolis, pero con otro resultado. La diferencia es justamente que Demóstenes no participa en ella y es Cleón quien está al mando. A pesar de esto, Tucídides vuelve a recurrir a la oposición de caracteres y en este caso se da con el héroe lacedemonio, Brásidas.

\section{EL SILENCIO Y LA VOZ: CLEÓN Y EL ANTI-ÊTHOS DEL GENERAL COMPETENTE DE BRÁSIDAS}

El hijo de Télide va ganando protagonismo a medida que la primera etapa de la guerra se va desarrollando: en sus apariciones en las Historiae el lector puede presenciar de algún modo su cursus honorum. Su heroicidad radica en parte en su velocidad, valor e intrepidez, todas cualidades asociadas al plano militar. ${ }^{23}$

El espartano aparece por primera vez, dijimos, en el sitio de Metone, una ciudad laconia que sufrió las represalias atenienses a causa de la primera invasión del Ática. Cuenta Tucídides:

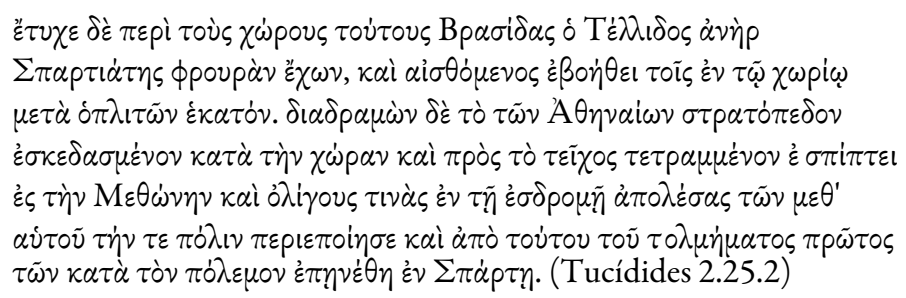

Sucedió que Brásidas, hijo de Télide, varón espartano se encontraba por esa región con una guarnición y una vez que se enteró de ello [del ataque a Metone] fue al auxilio con cien hoplitas. Tras atravesar corriendo el ejército ateniense que estaba disperso en el lugar y que estaba vuelto hacia la muralla, se precipita hacia Metone y tras perder a unos pocos de los que estaban con él en la embestida, salvó la ciudad y por este acto temerario fue celebrado como el primero en los asuntos de la guerra en Esparta.

Por un lado, Brásidas irrumpe en las Historiae como resultado de la týkhe. ${ }^{24}$ Por el otro, su velocidad ( $\delta(\alpha \delta \rho \alpha \mu \grave{\omega} \nu)$ se puede contraponer a la lentitud con la que se suele acusar a los espartanos (Tucídides 1.74.1, 84.2). Asimismo, su accionar, caracterizado por la audacia ( $\tau 0 \tilde{v} \tau 0 \lambda \mu \dot{\eta} \mu \alpha \tau \circ \varsigma)$ salva la ciudad y le hace ganar el reconocimiento de Esparta. ${ }^{25}$ Desde su primera mención, pues, es presentado como un guerrero intrépido y valeroso que logra salvaguardar Metone y que lo hace merecedor de los honores de su ciudad (Hornblower, 2003, I, p. 281).

En Tucídides 5.16.1 el enunciador-historiador afirma que su belicosidad está fundada en el éxito que tenía

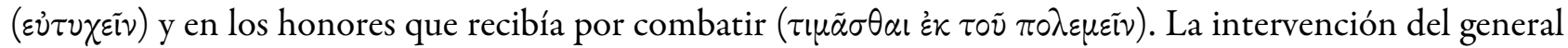
laconio en la guerra del Peloponeso, pues, se abre y se cierra con los mismos elementos: la eutýkhe ("éxito”) y la timé ("honor"). Con respecto al primer punto, es posible comprenderlo si tenemos en cuenta cómo es representando en el resto de la obra. Westlake (1968) considera que este pasaje nos prepara para la aristeía 
del espartano que tendrá lugar en la campaña del Norte y que culminará con una muerte y honores dignos de un héroe y fundador (p. 149 n.1).

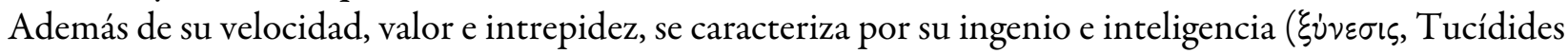

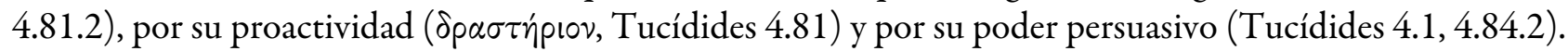
Algunos de estos atributos serán constatados, por ejemplo, en la primera batalla de Esfacteria (Tucídides 4.11-12) que es una verdadera aristeía.

Con el pasar de los episodios, el decir -así como el hacer- del espartiata resultará cada vez más importante. Es uno de los personajes que más habla en la obra: Tucídides transmite tres discursos en estilo directo (Tucídides 4.85-87, 4.126, 5.9) y otros tres en estilo indirecto (Tucídides 4.11, 4.114.3-5, 4.120.3). ${ }^{26}$ Esto se contrapone con el estereotipo del espartano lacónico, como el mismo Tucídides aduce (4.84.2). Brásidas es un ser excepcional en todo sentido y el enunciador-historiador se ocupa en hacerlo saber en el elogio de Tucídides 4.81. El éxito de la Campaña del Norte se debe no solo a su genio militar, sino principalmente a su don de palabra. Antes de atacar opta siempre por negociar y convencer de defeccionar a los aliados atenienses (Tucídides 4.71.1, 4.81.2, 4.83.2, 4.84.2): $\dot{\alpha} \pi \dot{\varepsilon} \sigma \tau \eta \sigma \varepsilon \tau \dot{\alpha} \pi \circ \lambda \lambda \dot{\alpha}$ (Tucídides 4.81.2, "en muchos casos hizo que se rebelaran ...”). En este sentido, es preciso tener en cuenta que el discurso del laconio es central a su personalidad y, por ende, el enunciador-historiador busca enfatizarlo. ${ }^{27}$

Nos vamos a centrar en las dos arengas (Tucídides 4.126, 5.9). Aunque la veracidad histórica de estos discursos ha sido puesta en duda, lo que nos preocupa es cómo estos operan en tanto estrategias discursivas para construir la representación de Brásidas. ${ }^{28}$ Las exhortaciones en estilo directo en Tucídides parecen cumplir funciones semejantes a las deliberativas al apelar al symphéron, desarrollos argumentativos como la explicación de una estrategia y hasta razonamientos complejos como los entimemas y esto se debería a que el "proceso de expansión literaria" del historiador tomó como modelo dicho género (Iglesias Zoido, 2000, p. 527). En un trabajo posterior, Iglesias Zoido sostiene que esta hibridez de las arengas en estilo directo se debe a que Tucídides crea un nuevo tipo de parainesis a partir de la combinación de dos líneas de argumentación: una explicativa (la didakhé, cf.Tucídides 4.125.4, 126.1) influida por la oratoria deliberativa que busca "ofrecer un cuadro claro y convincente de la situación" y otra exhortativa (parakéleusis, cf. Tucídides 5.10.1) "deudora del modelo homérico y que (...) busca enardecer a los combatientes"(2008, p. 37).

En la arenga de Tucídides 4.126 encontramos a los espartanos en una situación de extrema dificultad. Estos y sus aliados macedonios -dirigidos por Pérdicas- estaban acampados a cierta distancia los unos de los otros para atacar a Arrabeo; sin embargo, los ilirios, llamados bárbaroi (Tucídides 4.125.1, 4.127.1, 4.127.2), los traicionan y se pasan del lado del enemigo. Esto provocó que durante la noche los macedonios, "apresados por el pánico" e "incapaces de moverse” ( $\phi \circ \beta \eta \theta \dot{\varepsilon} \nu \tau \varepsilon \varsigma, ~ \dot{\varepsilon} \kappa \pi \lambda \dot{\eta} \gamma \nu v \sigma \theta \alpha$ l, Tucídides 4.125.1), abandonaran a los espartanos y calcídicos. Ante tal adversidad, Brásidas define la estrategia para realizar la retirada, eligiendo cerrar la marcha él mismo con trescientos hombres escogidos (Tucídides 4.125.2-3). Su arenga es presentada en términos de parakéleusis por él mismo:

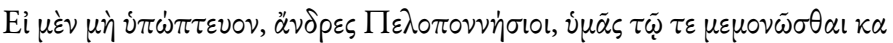

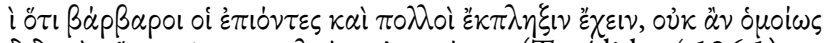

$\delta 1 \delta \alpha \chi \dot{\eta} \nu \check{\alpha} \mu \alpha \tau \tilde{\eta} \pi \alpha \rho \alpha \kappa \varepsilon \lambda \varepsilon \dot{\sigma} \sigma \varepsilon l$ ह่ $\pi \circ 1 \circ \dot{\mu} \mu \eta \nu$. (Tucídides 4.126.1)

Si no sospechara, peloponesios, que ustedes tienen un terror que los paraliza por el hecho de que se han quedado solos y porque los atacantes son bárbaros y muchos, no haría una instrucción semejante a la vez de una exhortación.
}

Para él mismo, su oratio es una "enseñanza" y una "exhortación”. La impronta didáctica se destaca, pues, desde un comienzo en el vocabulario utilizado. Didakhé es utilizada dos veces (Tucídides 4.126.1, 4) y

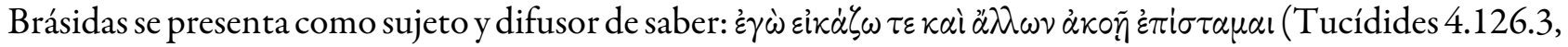
"yo infiero y también sé por haber escuchado a otros"). La ignorancia que esta didakhé busca combatir está fundada en la ả $\pi \varepsilon i p i \alpha$ ("falta de experiencia”, Tucídides 4.126.3) de sus soldados sobre aquellos contra quienes deben enfrentarse y esta "enseñanza verdadera” debe darles más confianza al defenderse ( $\delta\llcorner\delta \alpha \grave{\eta}$ 
$\dot{\alpha} \lambda \eta \theta \dot{\eta} \varsigma, \dot{\varepsilon} \theta \dot{\alpha} \rho \sigma v v \varepsilon \tilde{\alpha} \lambda \lambda_{0 \nu}$, Tucídides 4.126.4). ${ }^{29} \mathrm{Al}$ final del combate, y si hacen lo que su líder les ha indicado,

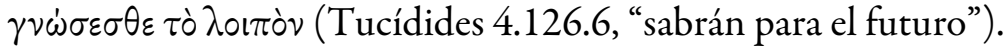

Para argumentar, Brásidas adopta pues un êthos didáctico, el cual se evidencia a partir de dos estrategias retóricas concretas: el uso continuo del argumento por el nexo causal y la disociación de nociones, fundada en la oposición ser/parecer. Desde un punto de vista pathético el laconio debe neutralizar el temor que puedan sentir sus soldados ante la situación apremiante en la que se encuentran y, asimismo, incentivar el valor -lo propio de la parainesis tradicional-, ${ }^{30}$ y, en este sentido, las técnicas argumentativas utilizadas no son una elección nimia. ${ }^{31}$ El hecho de proveer conocimiento certero y causas o justificaciones para sus afirmaciones permite amainar la ola de terror que corría por el ejército.

La intención por explicar las causas se evidencia por el asiduo uso del conector $\gamma \grave{\alpha} \rho$-cinco veces (Tucídides 4.126.2, 4, 5-x3-)- en un discurso de apenas 339 palabras. ${ }^{32}$ Asimismo, encontramos las conjunciones causales ö $\tau \iota$ y oi (Tucídides 4.126.1,2). A estos números habría que incluir otro tipo de construcciones causales, como son los circunstanciales y complementos circunstanciales de causa e incluso las construcciones de participio con matiz causal, que dan también una cifra de seis - sin contar las mencionadas anteriormente-. Desde un punto de vista pragmático, el uso de la justificación es una estrategia de la cortesía positiva para hacer más claro su mensaje, algo en lo que Cleón fallaba en su discurso ante la Asamblea (Tsakmakis \& Kostopoulos, 2011, p. 178). ${ }^{33}$

Por otra parte, la disociación de nociones supone una "unidad primitiva de los elementos confundidos en el seno de una misma concepción, designados por una misma noción" (Perelman \& Olbrechts-Tyteca, 1994, p. 628). Y es, efectivamente, en base a la distinción apariencia/realidad que Brásidas opera la disociación sobre los ilirios, los bárbaros que tienen tal fama de belicosidad al punto de provocar el temor y la huida de los macedonios: ${ }^{34}$

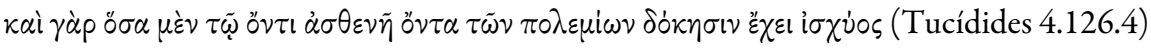

Pues aquello del enemigo que tiene apariencia de fuerza es en realidad débil...

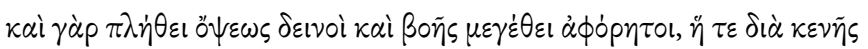

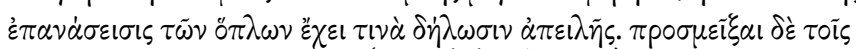

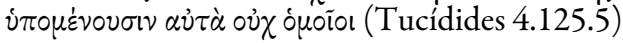

Pues también son terribles por la gran cantidad que se ve y son irresistibles por la magnitud del griterío y la vana manera de blandir sus armas tiene cierta muestra de amenaza. Pero no son los mismos para entablar combate con los que se atreven a hacer estas cosas.

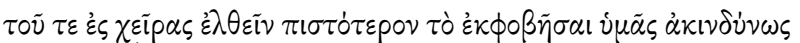
$\dot{\eta} \gamma \circ \tilde{\nu} \nu \tau \alpha \iota \cdot$ (Tucídides 4.126.5)

... y consideran que es más seguro el asustarlos a ustedes sin correr peligro que el ir a las manos.

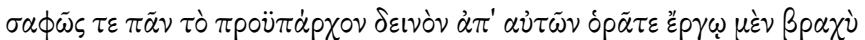

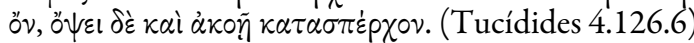

Y evidentemente verán que todo lo terrible de parte de ellos que hacen al principio, por un lado, es de hecho insignificante y, por el otro, que es apremiante a la vista y al oido.

La representación de los enemigos está firmemente construida sobre el ser y el parecer. ${ }^{35}$ Los espartanos deberán luchar con los ilirios verdaderos, no con aquellos que se muestran de un determinado modo. Esta distinción es la que dará lugar a una contraposición sobre los modos de pelear que tienen ellos y sus enemigos y, por consiguiente, a una construcción antitética entre los atacantes y los defensores. Si los ilirios no guardan una formación regular ( 4.126.6) que grita y blande las armas vanamente (Tucídides 4.126.5), Brásidas exhorta a sus hombres a

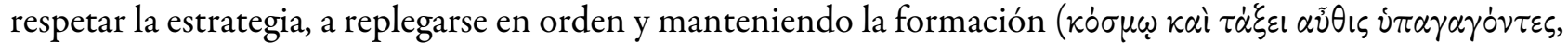

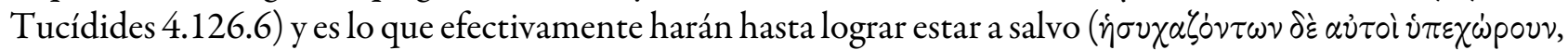
Tucídides 4.127.2). La diferencia entre unos y otros radica en dos valores que se suponen mutuamente lo 
kalón y la andreía (Tucídides 4.126, 6; cf. 4.126.5): mientras que el primero es uno de los fines del género epidíctico (Arist. $R$ h. 1358 b22 y ss.), el segundo es el propio de las arengas. ${ }^{36}$ La apelación a estos valores abren la sección propiamente parakeleumastiká (Tucídides 4.126.5-6) y se asocia con la construcción de un êthos heroico. Asimismo, de las dieciséis menciones que hay de la andreía en la obra tucidídea, dos pertenecen a esta arenga y, sorpresivamente, es aplicada a los enemigos para ser negada. La verdadera andreía será la de sus propios soldados cuando no cedan ante las manifestaciones del atacante y mantengan la formación, es decir, cumplan la estrategia que su líder les ha encomendado. En su apelación al valor y a la lucha es posible reconocer un êthos discursivo heroico. En la oratio de Acanto (Tucídides 4.85-87) también lo encontramos cuando afirma que los espartanos no recibirían ni gloria ni honor ( $\tau \mu \tilde{\eta} s$ kai $\delta \delta \dot{\xi} \eta s$, Tucídides 4.86.5) si permitieran que los atenienses esclavicen a todos y exhorta a la ciudad a abrazar la ải $\delta 10 \nu ~ \delta o ́ \xi \alpha \nu$ (Tucídides 4.87.6, "gloria eterna").

La narración posterior confirma el griterío y tumulto ocasionados por los bárbaros; estos no resultan efectivos con los griegos y finalmente los enemigos detienen la persecución. De este modo, Brásidas configura un êthos complejo de general competente, el cual se funda en los dos éthe mencionados, el didáctico y el heroico.

El contexto de la segunda arenga (Tucídides 5.9) es distinto. Hacia el 422 a.n.e., Esparta y Atenas venían de un armisticio de un año con una breve extensión, pero eso no evitó que algunas ciudades se pasaran al

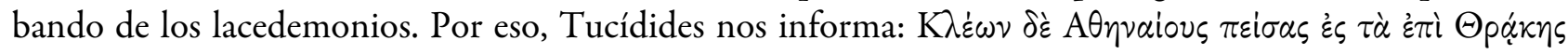

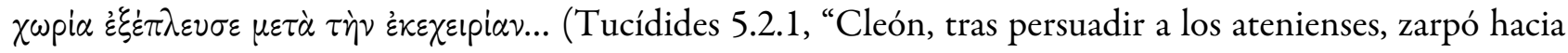
la zona de Tracia después del armisticio...”). ${ }^{37}$ Después de recuperar Torone (Tucídides 5.3), el ateniense toma Eyón como base para recuperar Anfípolis (Tucídides 5.6). Cleón decide reconocer el área y esto le permite a Brásidas saber que sus propias tropas son inferiores en términos de cualidad, por lo que recurre a una estratagema $(\tau \dot{\varepsilon} \chi \nu \eta)$ : elige a ciento cincuenta espartanos para atacar a los atenienses y el resto hará un segundo ataque desde otra puerta (Tucídides 5.8). ${ }^{38}$

Esta arenga presenta elementos comunes con la anterior, por ejemplo, adopta un êthos didáctico al explicar la estrategia que adoptará ( $\delta 1 \delta \dot{\alpha} \xi \omega$, Tucídides 5.9.2; $\delta \varepsilon \dot{\xi} \xi \omega$, Tucídides 5.9.10) y porqué ( $\gamma \dot{\alpha} \rho$, Tucídides 5.9.3, 8; $\dot{\omega} \varsigma$, Tucídides 5.9.3). Si bien se dirige a todos los soldados ( $\tau 0 \dot{\varsigma} \varsigma \pi \dot{\alpha} \nu \tau \alpha \varsigma \sigma \tau p \alpha \tau i \dot{\omega} \tau \alpha \varsigma$ ), apostrofa a los dos

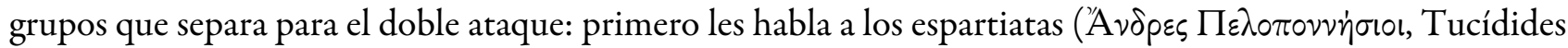
5.9.1) que lo acompañarán al principio, y luego a Cleáridas (K $\lambda \varepsilon \alpha p i \delta \alpha$, Tucídides 5.9.7) y al resto de las

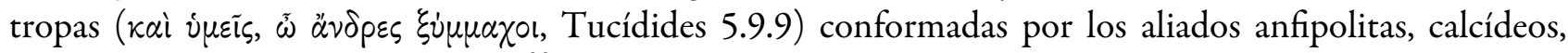
argilios y probablemente mircinios. ${ }^{39}$ En este sentido, la naturaleza de la estrategia se reproduce en la doble exhortación y en la explicación de lo que cada grupo deberá hacer.

A esto cabe agregar la apelación a un êthos heroico, el cual se delinea en múltiples puntos del discurso y que se asocia con la función tradicional de la arenga. Lo primero que hace es interpelar a los peloponesios por el

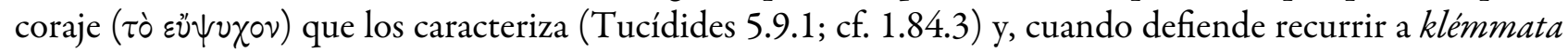
(“ardides”), lo hace en pro de la $\kappa \alpha \lambda i \sigma \tau \eta \nu \delta o ́ \xi \alpha \nu$ (“fama más hermosa”). ${ }^{40}$ Esto, sostiene el hijo de Télide, no

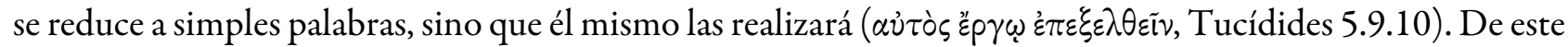
modo, Brásidas afirma nuevamente que habrá una concordancia entre sus dicta (la necesidad de ser valiente) y sus facta.

Por último, el discurso también cumple con lo que Luschnat llama "técnica de preparación" en tanto que la carrera de Brásidas mencionada en Tucídides 5.9.6 ocurre en 5.10.6 y el ataque de Cleáridas de 5.9.7 se cumple en 5.10 .7 (en Hornblower, 2004, II, p. 441). ${ }^{41}$ El efecto de ello es que las previsiones del general espartano se cumplen y dado que el análisis que realizó se confirma, se explica por qué la estrategia pergeñada tiene éxito. ${ }^{42} \mathrm{Al}$ igual que en la arenga anterior, Brásidas construye un êthos complejo de general competente, el cual se funda en los dos éthe que reconocimos: el didáctico y el heroico, ambos asociados con las dos funciones que adoptan la arengas en la obra tucidídea. 
Ante dicha situación, la figura de Cleón entra en clara contraposición. En primer lugar, el enunciadorhistoriador en ningún momento le adjudica la palabra, si no es en la Asamblea. No solo irrumpe en los hechos de Anfípolis habiendo persuadido de que lo enviaran como comandante de la campaña en la Calcídica, sino que en el libro anterior, mientras Tucídides narraba las acciones del hijo de Télide, el

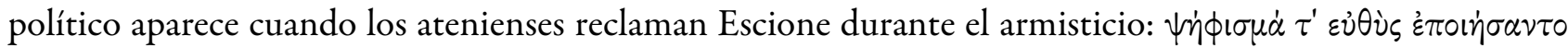

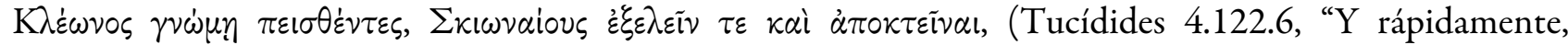
persuadidos por la propuesta de Cleón, hicieron un decreto, tomar a los escioneos y también matarlos"). ${ }^{43}$ En ambos casos, entonces, el político participa de una reunión en la Asamblea y su decir resulta lo suficientemente persuasivo para vencer. ${ }^{44}$

En cambio, durante la expedición del Norte Cleón se caracteriza por el silencio. Solo en el libro V mientras el enunciador-historiador refiere dos discursos en estilo directo del espartano (Tucídides 5.9, 5.10.5), apenas dará cuenta de uno brevísimo en estilo indirecto del hijo de Cleeneto. Esta mudez discursiva, veremos, entra en relación con sus cualidades como comandante de la fuerza y la derrota de la campaña que tenía por objetivo recuperar las póleis que se habían sublevado y en particular Anfípolis. ${ }^{45}$

Cleón recupera algunas ciudades, pero su objetivo es Anfípolis y toma Eyón como base. Mientras tanto, el general espartano se alista en Cerdilio para poder ver cada movimiento que hacen los atenienses (Tucídides 5.6.3): de hecho, él espera que el ejército ateniense se ponga en movimiento y ataque Anfípolis, haciendo

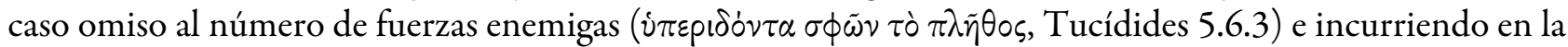
kataphrónesis ("arrogancia” o incluso "menosprecio") (Gomme, 1956, III, p. 642). Y justamente es lo que sucede:

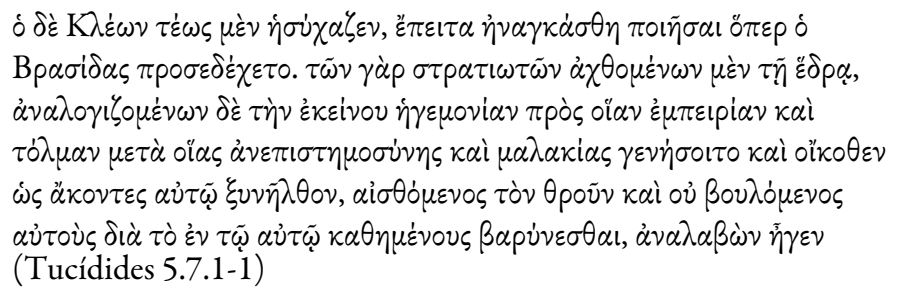

Pero durante un tiempo Cleón se mantuvo [lit. mantenía] quieto, entonces se vio obligado a hacer lo que Brásidas esperaba. Puesto que los soldados estaban irritados por estar sentados allí y reflexionaban sobre la conducción de aquel [de Cleón],[cómo] una experiencia y valentía tales [las de Brásidas] se encontrarían con una ignorancia y una cobardía tales [las de Cleón] y cuán involuntariamente habían partido de Atenas con él [Cleón], [él] sabiendo que murmuraban y no queriendo que estos se apesadumbraran porque permanecían en el mismo lugar, tras levantar campamento, los condujo.

En este pasaje se pone en primer plano la cuestión de la hegemonía cleoniana: los soldados se sienten inquietos por permanecer en el mismo lugar y, sobre todo, por quien los lidera. ${ }^{46}$ En este sentido, la oposición entre Brásidas y Cleón excede la opinión del enunciador-historiador y la encontramos también en las reflexiones de los hoplitas que guía el político. La contraposición se da pues en términos de la experiencia, por un lado, y la valentía, por el otro. Serán estos dos elementos los que entren en juego hacia el final del episodio, junto con la estrategia, y los que en algún punto justifiquen la construcción del êthos en las arengas de Brásidas. ${ }^{47}$

En el episodio de Anfípolis encontramos los elementos que vimos en Pilos, pero asociados al político para realzar su incapacidad como comandante: plantea una estrategia que no es capaz de seguir, su experiencia con Pilos -la única que tiene según Tucídides- no le trae ningún provecho y actúa como un cobarde (Tucídides 5.7). Nos encontramos con un líder que no lidera, sino que es liderado, tal como Tucídides había descrito a los políticos post-pericleanos, pero en este caso se da en el ámbito militar, de allí el uso del vocablo hegemonía. ${ }^{48}$ Cleón se ve obligado ( $\left.\dot{v} \alpha \gamma \kappa \dot{\alpha} \sigma \theta \eta\right)$ a actuar en contra de lo que él planeaba pues, en palabras de Gomme, "no tenía el carácter para controlar" a sus soldados (1956, III, p. 637). ${ }^{49}$ En su arenga, Brásidas afirmará que uno de los factores que asegura el éxito es que los soldados le hagan caso a sus comandantes (Tucídides 5.9.9). ${ }^{50} \mathrm{He}$ ahí su primer error como strategós: no está en dominio de la situación (Gomme, 1956, III, p.638). 
Lo cierto es que, según la narrativa, los soldados atenienses son renuentes a su conducción porque Cleón, con poca experiencia, no tenía chances en contraposición con Brásidas. El enunciador-historiador se hace eco del contraste que realizan los hoplitas entre los dos comandantes y es lo que ciertamente organiza el relato hasta la firma de la paz.

En este sentido resalta el uso del discurso en el episodio o, mejor dicho, su no utilización. Si Tucídides le da la palabra a Brásidas en estas dos ocasiones, en las que tiene todas las probabilidades en contra y resulta victorioso, el enunciador-historiador, por el contrario, no se la dará a Cleón. En un solo momento referirá que haya dicho algo:

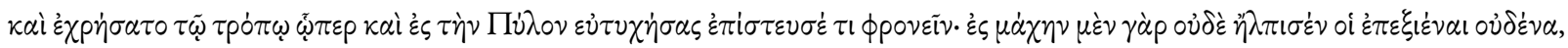

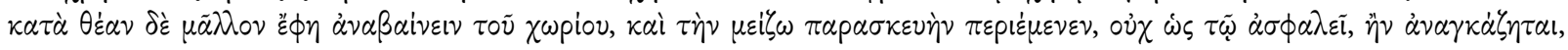

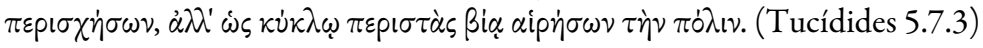

Y adoptó la misma actitud que había tenido en Pilos cuando había tenido éxito y confió en que era sensato. Pues ni siquiera pensó que nadie saliera a presentarle batalla, sino que dijo que más bien subía a la zona para hacer un reconocimiento y esperaba más refuerzos, no por debilidad si se veía obligado [a luchar], sino para rodear la ciudad y tomarla por asalto.

Aquí es en el único momento en el que emerge la voz de Cleón. Si el estilo indirecto apunta a poner énfasis el contenido de lo dicho, lo cierto es que su discurso toma la forma de una apología que explica por qué esperaba los refuerzos y rechaza la debilidad de su propio ejército. El discurso de justificación se da cuando el político emite declaraciones para defenderse de las críticas o acusaciones que se le dirigen y funciona como un contrapeso. ${ }^{51}$ Sin embargo, este tipo de discurso es un "cuchillo de doble filo" puesto que, si bien busca protegerse de la crítica, refuerza al mismo tiempo la existencia de esta. Si sus soldados cuestionaban su liderazgo, este discurso fortalece su representación como un general débil. Dichas palabras en estilo indirecto simplemente tienen el efecto de menoscabar aún más su autoridad como general. $\mathrm{Al}$ mismo tiempo, su estrategia es la misma que en Pilos: tomar por la fuerza su objetivo (Nikolaidis, 1990, p. 92). ${ }^{52}$ En cambio, vimos que Brásidas, incluso después de reconocer que tiene un ejército inferior en calidad, está dispuesto no solo a exhortar a sus tropas, sino a explicarles cómo deben atacar.

Este punto, creemos, no ha sido lo suficientemente remarcado por la crítica. ${ }^{53}$ Cleón, el pithanótatos tôu démou, no les habla a sus soldados para darles confianza, ni explicarles su estrategia. ${ }^{54}$ En cambio, Brásidas exhortará a sus fuerzas en dos ocasiones solo en este episodio (Tucídides 5.9, 5.10.5). Esto nos confirma que para Tucídides la verdadera arena de la demagogía era la política y no la militar. Si el líder político no se distingue del militar por la identidad entre el ciudadano y el soldado, lo cierto es que esto no ocurre en Cleón y sí, por el contrario, se da en el lacedemonio. Si el hijo de Télide construye una imagen de sí de general competente (fundado a partir de los éthe didáctico y heroico), el enunciador-historiador le adjudica por contraposición al ateniense una antiheroica y cobarde. Mientras que los lacedemonios y sus aliados tienen el

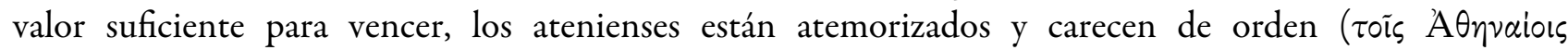

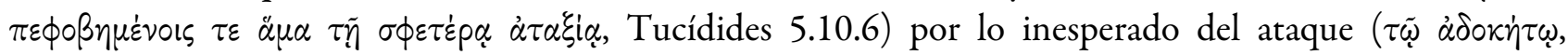
Tucídides 5.10.7). ${ }^{55}$ Esto se da por la incapacidad de previsión que tiene Cleón, así como por su desconocimiento de la rutina militar al dar la señal de retirada - posiblemente con una trompeta- y luego las órdenes verbales de cómo hacerlo: esto habría confundido a los soldados, haciendo que unas unidades se movieran y los otros esperaran las órdenes. ${ }^{56}$ En cambio, Brásidas es capaz de pronosticar la desorganización de sus enemigos ( $\dot{\alpha} \tau \dot{\alpha} \kappa \tau \omega \varsigma$, Tucídides 5.9.3) y su miedo ( $\phi \circ \beta \circ \tilde{v} v \tau \alpha$, Tucídides 5.9.7; $\phi \circ \beta \eta \theta \tilde{\eta} v \alpha$, Tucídides 5.9.8). Esta oposición se vehiculiza por medio de la correspondencia entre lo afirmado por las palabras del hijo de Télide y lo narrado por el enunciador-historiador.

Si bien la inmovilidad al principio responde a la prudencia y no a la cobardía por estar esperando los refuerzos (Hornblower, 2004, II, p. 438), esta última eventualmente emerge y es la que da lugar a que Cleón 
muera por una jabalina de un peltasta mircino en la huída $(\phi \varepsilon \dot{\gamma} \gamma \omega \nu) .{ }^{57}$ Asimismo, el general se contrapone con -al menos una parte de-sus liderados, pues el ala derecha permanece en su lugar:

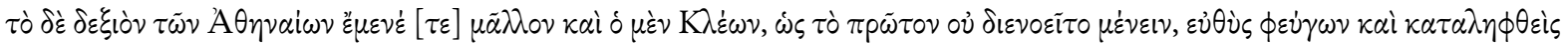

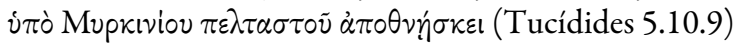

El ala derecha de los atenienses resistía más y Cleón, puesto que desde un principio había decidido no resistir, al punto huyendo y alcanzado por un peltasta mircinio muere.

La oposición se da no solo por el uso del verbo ménein, que se afirma en unos y se niega en el otro, sino también se podría pensar el $\mu \dot{v} v$ con un sentido concesivo (Gomme, 1956, III, p. 652). Al respecto, resulta interesante recordar las palabras de Saxonhouse sobre la guerra: "To engage in war is the fullest expression of involvement in political life, for it means to sacrifice all, one's mind and one's body, for that which is public (...) there is the complete obliteration of all that is private for the sake of the community" (1980, p. 67).

Al describir la muerte de Cleón en la huida, Tucídides expone la falta de involucramiento en el conflicto cuya continuación él mismo había incitado. Una muerte así era el más grande deshonor porque implicaba una actitud cobarde y nuevamente debemos rememorar las palabras de Brásidas sobre cómo uno de los factores del éxito es que los soldados les hagan caso a sus comandantes.

Vemos operar la selección, que supone la mención y el silencio, y concuerda con la representación discursiva de Brásidas como general competente y de Cleón como cobarde y líder militar inepto, lo cual se evidencia con la muerte de ambos personajes. Mientras que Brásidas es honrado una vez muerto por los ciudadanos de Anfípolis quienes le crean competencias y festivales en su honor "como a un héroe" (Tucídides 5.12), Cleón es llevado con el resto de los cadáveres a Atenas sin una mención explícita (Tucídides 5.11); de nuevo silencio. Después de 5.16 el ateniense no será mencionado nuevamente, mientras que Brásidas es referido en relación con sus soldados que participarán en la batalla de Mantinea (Tucídides 5.67, 5.71, 5.72) o que han sido libertados -en caso de haber sido hilotas- por su valor (Tucídides 5.34) o a causa de sus hazañas (Tucídides 5.110). ${ }^{58}$ De este modo, cada uno obtiene los honores que se merece: uno el recuerdo, otro el olvido.

\section{ConcLuSIONES}

En líneas generales, se puede decir que Tucídides le adjudica a Cleón un êthos relacionado con el pólemos, el de general incompetente y cobarde. Si bien defiende la continuación de la guerra, el enunciador-historiador recurre a dos procedimientos para construir la imagen. Por un lado, en Pilos apela a la macroestrategia de la focalización del accionar de Demóstenes y esto implica simultáneamente un borramiento de la participación de Cleón. Tres son las estrategias que se vinculan a esta: la descalificación del adversario -como alguien que siente aprehensión para tomar el mando-, la explicación y adjudicación del plan al hijo de Alcístenes y los ecos de su experiencia militar. Serán estos dos últimos puntos los que expliquen el éxito. Cabe resaltar, asimismo, que la participación de Cleón en la campaña se restringe a las situaciones diplomáticas, no bélicas (Tucídides 3.40.4, 36.1, 38).

En el caso de Anfípolis se da una oposición con la figura de Brásidas y que se explicita en algún modo en 5.16.1, pero que los encontramos en los discursos referidos. El análisis de las arengas en particular permite reconstruir un êthos complejo de general competente que se funda en dos imágenes, la didáctica y la heroica. Ambas se relacionan con las dos líneas de argumentación que conforman las arengas en las Historiae, la explicativa y la exhortativa. Las orationes en Tucídides 4.126 y 5.9 cumplen su función y los episodios terminan con una victoria lacedemonia.

Por el contrario, Cleón se caracteriza por la mudez y no dirige ninguna palabra de aliento a sus soldados, cuando se encuentran irritados por no moverse y porque son conscientes de la diferencia entre los dos comandantes. La hegemonía cleoniana es puesta en entredicho por los mismos soldados y el demagogós no 
es capaz de hacerle frente a ello. Si bien no hay arengas, es posible reconocer un breve discurso en estilo indirecto que toma la forma de una justificación o apología de por qué puso en movimiento sus tropas, lo cual socava aún más su autoridad. A diferencia de lo que se hubiera esperado del pithanótatos toû démou, no hay más que silencio en su actuación militar y, al mismo tiempo, no controla a sus liderados. En pocas palabras, en contraposición con el espartiata, el ateniense -en tanto su anti-êthos-es un general incompetente y se puede reconocer un marcado contraste entre su discurso belicista y su actitud con la guerra. De este modo, la representación que hace el enunciador-historiador se funda en una técnica polémica, la descalificación del adversario, la cual inserta el texto tucidídeo en una disputa sobre cómo debe ser un líder. Y Cleón claramente no responde a la norma.

\section{EDICIONES Y COMENTARIOS}

Gomme, A. W. (Com.) (1956). A Historical Commentary on Thucydides. Books II-III (vol. II). Oxford: Clarendon Press.

Gomme, A. W. (Com.) (1956). A Historical Commentary on Thucydides. Books IV-V.24 (vol. III). Oxford: Clarendon Press.

Gomme, A. W. Andrewes, A. \& Dover, K.J. (Com.) (1981). A Historical Commentary on Thucydides (vol. V). Oxford: Clarendon Press.

Hornblower, S. (Com.) (2003 [1991]). A Commentary on Thucydides. Books I-III. Oxford: Clarendon Press. Hornblower, S. (Com.) (2004 [1996]). A Commentary on Thucydides. Books IV-V.24. Oxford: Clarendon Press.

Hornblower, S. (Com.) (2008). A Commentary on Thucydides. Books V.24-VIII. Oxford: Clarendon Press.

Jones, H.S. \& Powell, J.E. (Eds.) (1942). Thucydidis Historiae (2 vols.). Oxford: Clarendon Press.

Meiggs, R. \& Lewis, D. M. (1968) (Eds.). A Selection of Greek Historical Inscriptions to the end of the Fifth Century B.C. Oxford: Oxford UP.

Rhodes, P. J. (1998) (Ed.). Thucydides. History. Book IV-V.24. Oxford: Aris \& Phillips.

\section{InSTRUMENTA STUDiorum}

Bailly, A. (2000 [1894]). Dictionnaire Grec-Français. Paris: Hachette. [Bailly]

Bétant, E. A. (1843) Lexicon Thucydideum (vol. I). Génève: Carey/Kessman.

Bétant, E. A. (1847) Lexicon Thucydideum (vol. II). Génève: Carey/Kessman.

Liddell, H. \& Scott, R. \& Jones, H. S. (1996). A Greek-English Lexicon. Oxford: Clarendon Press (= LSJ).

Real Academia Española (2020). Diccionario de la Real Academia Española (versión 23.4). Madrid: Real Academia Española. En: http://www.rae.es/recursos/diccionarios/drae; [Acceso: 17/06/2020] [DRAE]

Smyth, H.W. (2013 [1920]). Greek Grammar. Cambridge (MA): Harvard University Press.

\section{Bibliografía CRÍTICA}

Adcock, F. E. (1963). Thucydides and his History. Cambridge: Cambridge University Press.

Anderson, J. K. (1965). Cleon's orders at Amphipolis. JHS, 85, 1-4.

Angenot, M. (1995 [1982]). La parole pamphlétaire. Paris: Payot.

Baldwin, B. (1968). Cleon's Strategy at Amphipolis. Acta Classica, 11, 211-214.

Balot, R. (2014). Courage in the Democratic Polis. Ideology and Critique in Classical Athens. Oxford: Oxford University Press. 
Bassi, K. (2003). The Semantics of Manliness in Ancient Greece. En R. Rosen \& I. Sluiter (Eds.), Andreia. Studies in Manliness and Courage in Classical Antiquity (pp. 25-58). Leiden/Boston: Brill.

Charaudeau, P. (2008 [2005]). Discurso politico. São Paulo: Contexto.

Clark, M. (1995). Did Thucydides Invent the Battle Exhortation? Historia: Zeitschriftfür Alte Geschichte, 44 (3), 375-376.

Connor, W. R. (1984). Thucydides. Princeton: Princeton University Press.

Connor, W. R. (1992 [1971]). The New Politicians of Fifth-Century Athens. Indianapolis: Hackett.

de Romilly, J. (1947). Thucydide et l'impérialisme athénien, la pensée de l'historien et la genèse de l'auvre. Paris: Les Belles Lettres.

Erhardt, C. T. H. R. (1995). Speeches before Battle?. Historia: Zeitschrifffür Alte Geschichte, 44 (1), 120-121.

Finley, J. Jr. (1942). Thucydides. London: Humphrey Milford.

Flower, H. I. (1992). Thucydides and the Pylos Debate (4.27-29). Historia: Zeitschriftfür Alte Geschichte, 41(1), 40-57.

Fornara, C. (1971). The Athenian Board of Generals from 501 to 404. Wiesbaden: Franz Verlag.

Franco San Román, M. (2016). El êthos de Cleón en la antilogía de Mitilene (Thuc.3.36-40). En E. Lopes Piris \& I. C. Michelan de Azevedo \& G. de Oliverira Santos Lima (Orgs.), Anais do III Seminário Internacional de Estudos sobre Discurso e Argumentaçao. Ilheus: Editus.

Gomme, A. W. (1954). Thukydides and Kleon: the second battle of Amphipolis. Helleniká,13, 1-10.

Hansen, M. H. (1993). The Battle Exhortation in Ancient Historiography. Fact or Fiction? Historia: Zeitschrifffür Alte Geschichte, 42(2), 161-180.

Hansen, M. H. (1999 [1991]). The Athenian Democracy in the Age of Demosthenes: Structure, Principles, and Ideology. Norman: University of Oklahoma Press.

Heilke, T. (2004). Realism, Narrative, and Happenstance: Thucydides' Tale of Brasidas. The American Political Science Review, 98(1), 121-138.

Holladay, A. J. (1978). Athenian Strategy in the Archidamian War. Historia: Zeitschriftfür Alte Geschichte, 27(3), 399-427.

Hornblower, S. (Ed.). (1987). Thucydides. London: Duckworth.

Huart, P. (1968). Le vocabulaire de l'analyse psychologique dans l'auvre de Thucydide. Paris: Klincksieck.

Iglesias Zoido, J. C. (1995). La argumentación en los discursos deliberativos de Tucídides y su relación con la normativa retórica del siglo $I V$. Cáceres: Universidad de Extremadura.

Iglesias Zoido, J.C. (2000). ¿Se pronunciaron realmente las arengas de Tucídides?: el testimonio de Th.VII, 61-70. Athenaeum, 88(2), 512-528.

Iglesias Zoido, J.C. (2008). La argumentación en las arengas militares de Tucídides. AC, 77, 19-40.

Kagan, D. (1974). The Archidamian War. Ithaca/London: Cornell UP.

Lafargue, P. (2013). Cléon. Le Guerrier d'Athéna. Paris: Ausonius.

Lambert, S. D. (2017). Two Inscribed Documents of the Athenian Empire The Chalkis Decree and the Tribute Reassessment Decree. AIO Papers 8. Disponible en: https://www.atticinscriptions.com/papers/aio-papers-8/ [Acceso: 12/04/2020]

MacLeod, C. W. (1983). Collected Essays. Oxford: Clarendon Press.

Mann, Ch. (2007). Die Demagogen und das Volk. Berlin: Akademie Verlag.

Marincola, J. (2007). Speeches in Classical Historiography. En J. Marincola (Ed.), A Companion to Greek and Roman Historiography (pp. 118-132). Malden: Blackwell.

Mitchell, B. (1991). Kleon's Amphipolitan Campaign: Aims and Results. Historia: Zeitschrift für Alte Geschichte, 40(2), 170-192.

Mossé, C. (1999 [1968]) Le rôle politique des armées dans le monde grec. En J.-P. Vernant (Dir.), Problèmes de la guerre en Grèce ancienne (pp. 291-302). Paris: Éditions de l'École des Hautes Études en Sciences Sociales. 
Murari Pires, F. (2003). Thucydide et l'assemblée sur Pylos (IV.26-28): rhétorique de la méthode, figure de l'autorité et détours de la mémoire. $A H B, 17,127-148$.

Nikolaidis, A. G. (1990). Thuc.4.28.5 (or Cleon at Sphakteria and Amphipolis). BICS, 37, 89-94.

Ober, J. (1989). Mass and Elite in Democratic Athens. Rhetoric, Ideology, and the Power of the People. Princeton: Princeton University Press.

Perelman, Ch. \& Olbrechts-Tyteca, L. (1994 [1958]). Tratado de la Argumentación. La nueva retórica. Madrid: Gredos.

Pritchett, W. K. (1973). The Woodheadean Interpretation of Kleon's Amphipolitan Campaign. Mnemosyne, 26(4), 376-386.

Reyes, G. (1995 [1993]). Los procedimientos de cita: estilo directo y estilo indirecto. Madrid: Gredos.

Rhodes, P. J. (2016). Demagogues and Demos in Athens. Polis, 33, 243-264.

Rosen, J. \& Sluiter, I. (2003). Andreia. Studies in Manliness and Courage in Classical Antiquity. Leiden/Boston: Brill.

Saldutti, V. (2014). Cleone, un politico ateniese. Bari: Edipuglia.

Saldutti, V. (2015). Sul demagogo e la demagogia in età classica. Una sintesicritica. Incidenza dell' antico, 13, 81-110.

Saxonhouse, A. W. (1980). Men, Women, War, and Politics: Family and Polis in Aristophanes and Euripides. Political Theory, 8(1), 65-81.

Sinclair, R. K. (1988). Democracy and Participation in Athens. Cambridge: Cambridge University Press.

Spence, I. G. (1995). Thucydides, Woodhead, and Kleon. Mnemosyne, 48(4), 411- 437.

Stahl, H.- P. (2003). Thucydides. Man's Place in History. Swansea: The Classical Press in Wales.

Tsakmakis, A. \& Kostopoulos, Y. (2011). Cleon's Imposition on his Audience. En G. Rechenauer \& V. Pothou (Eds). Thucydides - a Violent Teacher? History and Its Representations (pp. 171-183). Göttingen: V \& R Unipress.

West, A. B. \& Meritt, B.J. (1925). Cleon's Amphipolitan Campaign and the Assessment List of 421. AJA, 29(1), 59-69.

West, W. C. III (1973). The Speeches in Thucydides: A Description and Listing. En P. A. Stadter (Ed.), The Speeches in Thucydides. A Collection of Original Studies with a Bibliography (pp. 3-15). Chapel Hill: The University of North Carolina Press.

Westlake, H.D. (1968). Individuals in Thucydides. Cambridge: Cambridge UP.

Woodhead, A. G. (1960). Thucydides' Portrait of Cleon. Mnemosyne, 13(4), 289-317.

Worthington, I. (1987), Aristophanes' Knights and the Abortive Peace Proposals of 425 B.C. LAC, 56, 56-67.

Zavalijy (2020). Courage and Cowardice in Ancient Greece. From Homer to Aristotle. Kuwait: Springer.

\section{Notas}

1 Una versión preliminar del presente artículo fue presentada en el Ciclo de Conferencias de Investigadores en Formación "Violencia y política en las sociedades del Mediterráneo antiguo" organizado por el Programa de Estudios sobre las Formas de Sociedad y las Configuraciones Estatales en la Antigüedad y realizado en el mes de marzo de 2021. A la autora le gustaría agradecer los comentarios que recibió en aquel entonces y también por parte de los referatos anónimos de la revista, quienes han ayudado a mejorarlo. Asimismo, desea darles las gracias a su director, el Dr. Emiliano J. Buis, y a su co-directora, la Dra. Alejandra Vitale; su guía y lectura profunda han resultado indispensables para el desarrollo de esta investigación. Cualquier falla que pueda presentar el escrito, es de entera responsabilidad de la autora.

2 Resulta interesante que el enunciador-historiador resalte la capacidad oratoria de Cleón, pero que, en el caso de Pericles, sostenga que este es "poderosísimo en el discurso y en la acción" (Tucídides 1.139.4). Pareciera que en el Cleón la acción no tiene lugar, solo la palabra.

3 El êthos complejo es la imagen de sí que construye el orador y que, siendo estable, predomina a lo largo de su discurso y que se ve acompañado de una serie de éthe a los cuales el orador recurre para consolidar la fuerza perlocutiva asociada al êthos principal (Franco San Román, 2016).

4 Westlake (1968) sostiene que la principal función de Brásidas es la de remarcar el contraste con otros líderes espartanos con respecto a dos prerrequisitos de todo buen liderazgo: la capacidad de aprovechar oportunidades por medio de un accionar imaginativo y osado y, por el otro, la habilidad de ganar el apoyo de otros por medio del uso de la palabra hablada 
(p. 150). Si bien concordamos con Westlake en que hay una clara oposición del hijo de Télide con el resto de los dirigentes espartanos, creemos que su figura también apunta a resaltar las fallas de Cleón en la campaña de Tracia y la Calcídica.

5 La descalificación del adversario es una técnica refutativa que apunta a marcar una falta de legitimidad del blanco polémico y una justificación de ello (Angenot, 1995, pp. 225-228).

6 Cf. Saldutti (2014), quien afirma que esto suponía volver a la política de los años 450 a.n.e. (p. 140). De hecho, el autor vincula a Cléon con las campañas de Beocia del año siguiente (Saldutti, 2014, pp. 145-150). Empero Tucídides no lo menciona. Según MacLeod (1983), Pilos cumple un rol en la tragedia de los excesos que Tucídides narra: "in their success, there is an error, and in their failure they enact that error again and pay for it" (p. 143). Saldutti (2014) considera que se trataría de una estrategia contraria a la pericleana, en tanto que el Alcmeónida no habría tenido en cuenta ni las condiciones urbanísticas que llevaron al hacinamiento de la población ni el factor económico de sostenimiento del imperio o la resistencia de los espartanos a la estrategia ateniense, cuestiones que Cleón habría intentado resolver con el cambio una estrategia más activa y una revisión de los montos provistos por las póleis súbditas (p. 141). Sobre la cuestión financiera, cf. Saldutti (2014, pp. 130-136). Hay quienes coinciden en relacionarlo con la revaluación de los tributos conocido como el "decreto de Túdipo" (IG I3 71) que tiene por objetivo el recaudar dinero para la guerra, dado que los valores se duplican o triplican con respecto a años anteriores, pero no hay evidencia concreta que confirme el vínculo con el político (Meiggs \& Lewis, 1969, pp.193-197; Mitchell, 1991, p. 170 y n.2; Saldutti, 2014, pp. 133-134; cf. Gomme, 1956, III pp. 500-505; Lambert, 2017, pp. 41-42). Meiggs y Lewis (1969) ven en el tono fuerte y altamente polémico del decreto una evidencia de que Cleón estaría relacionado con él (pp. 196-197).

7 Se ha discutido el cargo que ocupa Cleón en esta expedición. Murari Pires (2003) propone que ya había sido electo en el 425 a.n.e.; el problema de esta lectura es que conocemos los diez strategoí de ese año (cf. Fornara, 1971, p. 59) y Tucídides parece insistir en el carácter extraordinario del nombramiento, pues en ningún momento utiliza el título

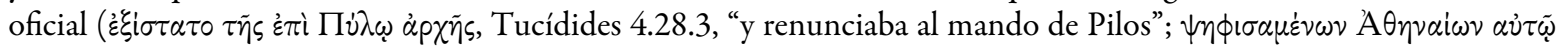

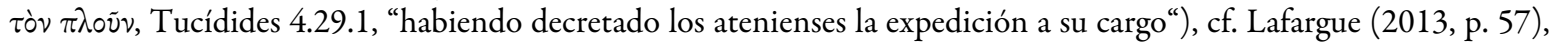
Saldutti (2014, p. 145 y n.38). En Nu.581-2 el coro afirma que Paflagonio -Cleón- fue elegido strategós, pero se trataría del año 424/3 a.n.e. (Fornara, 1971, pp. 59, 61). Fornara (1971) sostiene que Nicias no renunció a la strategía como magistratura, sino al mando (arkhé) de Pilos y no entiende que Cleón sea un undécimo general excepcional (p. 59; cf. Worthington, 1987, p. 58). Flower (1992), por su parte, ve en el tratamiento de Nicias mayor benevolencia que en el de Cleón pues el general solo habría reaccionado ante este y no habría presentado ninguna propuesta propia (p. 49).

8 Nikolaidis (1990) cuestiona que este éxito haya aumentado en gran medida el poder de Cléon al retomar a Gomme, quien considera que el político no habría sido electo general en 424 a.n.e. y Tucídides no lo menciona como tal (p. 90; sin embargo, Nu.581-2, cf. Fornara, 1971: pp. 59, 61). Empero, si en algo vale el testimonio aristofánico, Cléon recibió la sitesis en el Pritaneo y asientos de preferencia, lo que en términos simbólicos mostraría la importancia que llegó a tener.

9 Cf. Westlake (1968, pp. 72-73), Holladay (1978, pp. 424-425), Kagan (1974, p. 242-243), Mitchell (1991, p. 173), Hornblower (2004, II, pp. 188-189), Lafargue (2013, p. 57). Saldutti (2014) considera que Cleón al menos conocía el plan de Demóstenes con el cual habría estado en contacto (p. 143).

10 Sinclair (1988, p. 137), Ober (1989, pp. 91-3), Connor (1992, pp. 143-7); cf. Hansen (1999, pp. 269).

11 Cf. Ostwald (1986, p. 201), Ober (1989, p. 104-18), Connor (1992, p. 143-7), Mann (2007).

12 Cf. Tucídides 4.105.1; Demóstenes 1.22-3, 2.17.

13 Cf. Stahl (2003, p. 140). Finley (1942) sostiene la posibilidad de que Demóstenes haya sido la fuente de Tucídides sobre este episodio (p. 188). Westlake (1968) hipotetiza que pudo basarse en los informes del general o quizás habló con alguien muy cercano a él (p. 106).

14 El autor relaciona, así, el verbo deidein con nomizein y gignóskein.

15 "His brave words are undercut by the historian's previous revelation of his secret fears" (Flower, 1992, p. 46). Por el contrario, Lafargue (2013) lee en este episodio premeditación por parte de Cleón, pues sabe que Demóstenes atacará de manera inminente (p. 57).

16 La andreía, normalmente traducida por "coraje" o "valentía”, ha sido objeto de estudio del tomo compilado por Rosen y Sluiter (2003) y del trabajo más reciente de Zavaliy (2020). Balot (2014), por su parte, estudia el coraje en relación con el régimen democrático ateniense. Sobre la semántica de andreía y su relación con anér, cf. Bassi (2003). Connor (1984) resalta: "almost any Greek male would be outraged by such an insult and challenge his critic to do better" (p. 116). Nicias tenía ante sí dos opciones: adoptaba la estrategia de Cleón y partía a Pilos él mismo o lo que de hecho hizo (Nikolaidis, 1990, p. 91). Flower (1992) considera que la diferencia con Nicias radica en los tiempos de expedición, no en la sustancia o el propósito; si los atenienses no se apuraban, iban a perder la oportunidad (pp. 45-46).

17 “Andreia prototypically needs an agonistic context" (Rosen \& Sluiter, 2003, p. 8). De un modo similar, Zavaliy (2020) cuestiona la multiplicación de tipos de "coraje" y sostiene que el sentido original es el marcial, aquel desplegado por el soldado en la batalla (pp. 3-4, 16).

18 Kagan (1974) considera que Tucídides sobreestima el rol jugado por la týkhe y que es el genio de Demóstenes el que debe ser reconocido: "the entire campaign was conceived and executed by Demosthenes with a keen eye for the 
special opportunities offered by Pylos and Sphacteria. Success depended to some degree on luck, as it always does, but intelligence and good planning were present and vital” (p. 231); cf. de Romilly (1947, p. 151), Westlake (1968, pp. 107-109), Lafargue (2013, p. 58).

19 Lafargue (2013) ve en Aristófanes una referencia a que Cleón conocía perfectamente las intenciones de Demóstenes y que su accionar en la Asamblea en el enfrentamiento con Nicias todo habría estado calculado (p. 57; cf. Caballeros 75-76).

20 Lafargue (2013) sostiene que quizás el soldado provocó el incendio por orden de Demóstenes, pero sencillamente Tucídides no lo sabía; esto condiría con la imagen que construye del general (p. 58). "The Thucydidean realist world is a world of action and contingency, of human purposes and the vagaries of happenstance” (Heilke, 2004, p. 135).

21 Hornblower (1987) considera que Tucídides admira al general y que es el único que es capaz de aprender de su experiencia, así como de la de los otros (p. 158); cf. Tucídides 7.42.3. En el presente caso, a diferencia de Etolia (Tucídides 3.98.1) en donde los soldados se dieron a la fuga, la formación que estableció Demóstenes se mantuvo y eso también influyó en el resultado.

22 Westlake (1968) afirma que en ningún momento Tucídides evalúa la contribución de Demóstenes a una de las victorias atenienses más importantes, aunque no tiene problemas en definir la promesa de Cleón de tomar la isla en veinte días como $\mu \alpha \nu i \omega \delta \delta$ (Tucídides 4.39.3; p. 111). La ausencia de evaluación en contraposición con el político no debe ser tomada como un desmerecimiento de lo realizado por el hijo de Alcístenes, pues la narrativa se focaliza justamente en su figura y pone en evidencia que es el cerebro detrás de toda la estrategia militar, algo que el mismo Westlake (1968) rescata (pp. 97 y ss.).

23 Su unicidad lo lleva a Westlake (1968, p. 148) a afirmar que es la antítesis del líder espartano convencional.

24 Cf. Tucídides 4.70.

25 Hornblower (2003, I, p. 281), retomando a Lewis, cree ver en el uso del verbo epaineîn algún tipo de honra institucionalizada que no conocemos.

26 Para llegar a estas cifras nos basamos en el catálogo confeccionado por West (1973, pp. 7-15). Iglesias Zoido (1995) sigue este listado, pero considera que el autor incluyó elementos que "difícilmente pueden ser considerados como discursos" (p. 162). Por otra parte, el listado nos resulta incompleto ya que se podrían agregar otros discursos en estilo indirecto que West no tiene en cuenta -Tucídides 4.71 .1 (sobre sus planes de recuperar Nisea y entrar en Mégara) y Tucídides 4.78 (cuando intenta convencer a los tesalios de que lo dejen pasar por allí con su ejército) -y uno más en estilo directo (Tucídides 5.10.5). A pesar de ello, Brásidas es el tercer personaje cuyos discursos son más transmitidos, al seguir a Alcibíades y a Nicias que cada uno tiene trece; al espartiata le sigue Terámenes con cinco. Cabe agregar, asimismo, que se puede ver una notable diferencia entre la primera parte de la obra (Tucídides 1.1-5.24) con la segunda (Tucídides 5.25-8.108) en materia de discursos: el número aumenta sustancialmente en la última sección (cf. Westlake, 1968). Sobre la diferencia entre ambos estilos de cita, cf. Reyes (1995).

27 Para poner en perspectiva esta afirmación, basta citar el ejemplo de Arquidamo, el rey espartano que busca evitar la guerra, cuyas palabras son referidas solo cuatro veces y están principalmente asociadas a su actitud disuasoria (Tucídides $2.11,2.72 .1,2.72 .3,2.74 .2)$.

28 Si bien su existencia histórica ha sido cuestionada por Hansen (1993), quien ve en las exhortaciones una composición exclusivamente literaria, otros han reaccionado en contra de su tesis (Erhardt, 1995; Clark, 1995; Hornblower, 2004, II, pp. 82-83). Iglesias Zoido (2000) ve en las arengas en estilo directo una "creación literaria que no se corresponde con la realidad de lo pronunciado por los oradores”, aunque las verdaderas oraciones se adscribirían al género epidíctico (p. 527; cf. 2008). Nuestro trabajo es independiente de esta cuestión sobre la historicidad de las exhortaciones, pues vemos los discursos tanto en estilo indirecto como directo como estrategias del historiador para "pintar" con mayor detalle el carácter de los personajes que intervienen en sus Historiae, cf. Marincola (2007).

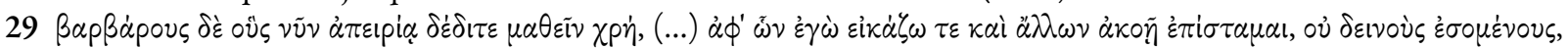
Tucídides 4.126.3, "Y es preciso que aprendan sobre los bárbaros a los que ahora temen por falta de experiencia (...) de los que yo infiero y también se por medio de lo que escuché de otros que no serán terribles".

30 Cf. Iglesias Zoido (2000, p. 29).

31 Es preciso recordar que las parainéseis tradicionales que encontramos en Homero (por ej. Il.2.110-141, 284-333, 336-368) e incluso Heródoto (8.83.1-2, 9.17.14) buscaban enardecer a los soldados.

32 Sobre la partícula $\gamma \dot{\alpha}$ p como conjunción causal, cf. Smyth $(2013, \$ 2810)$.

33 En efecto, Cleón en un discurso tres veces más extenso (1175 palabras) apela a $\gamma \grave{\alpha} \rho$ solo seis veces (Tsakmakis \& Kostopoulos, 2011, p. 178).

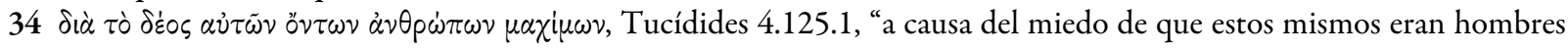
belicosos".

35 La narración confirma el griterío y tumulto ocasionado por los bárbaros y cómo no terminan siendo efectivos en los griegos, ya que estos actúan "en contra de lo esperado" ( $\pi \alpha \rho \grave{\alpha} \gamma \nu \omega \dot{\mu} \mu \nu$, Tucídides 4.127.1), detienen la persecución. 
36 Sobre el vínculo entre las arengas y el género epidíctico, cf. Iglesias Zoido (2000). Con respecto al entrecruzamiento de fines entre los distintos géneros discursivos, Iglesias Zoido (1995) reconoce que la rigidez con la que Aristóteles asocia a estos sería más bien aparente (p. 52); si bien cada uno de los géneros tiene sus fines (Retórica $1358 b 22$ y ss.), "no impide que algunos de estos elementos puedan jugar un papel destacado en un género distinto al que Aristóteles les asigna” ( $\mathrm{p}$. 52). En Retórica para Alejandro (1421 b15 y ss., 1427 b30 y ss.), recuerda el autor, los objetivos e intereses ayudan a determinar cuál debe ser más mencionado sobre los otros y no objeta su combinación (Iglesias Zoido, 1995, p. 53).

37 Veremos que esta es la segunda vez que se menciona al hijo de Cleeneto en los sucesos del Norte y nuevamente su primera acción es la persuasión. Hornblower (2004) considera que aquí es posible reconocer el modo “tendencioso" en que se estaría presentando la expedición como una iniciativa del político meramente ratificada por la Asamblea (II, p. 425), cf. Gomme (1956, II, p. 631). Es cierto también que ante la deserción de las póleis los atenienses sintieron ira (ópyìv

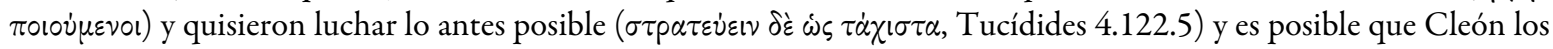
haya incitado una vez más a la guerra. De hecho, Nicias ya había tomado medidas para recuperar las ciudades súbditas perdidas (Tucídides 4.129-131). Fornara (1971) parece entender que el convencimiento fue que lo enviaran a él a Tracia, no la campaña en sí (p. 37 n.32).

38 Gomme (1956) cuestiona el número por ser una fuerza demasiado pequeña (III, p. 643).

39 Tucídides 4.103.3-4, 5.6.4. Gomme (1956) plantea que el primer apóstrofe sería una "simplificación convencional” y afirma que es mejor no intentar "visualizar" la exhortación (III, p. 643). Algunos críticos ven en la triple exhortación un problema porque el comentario de la oposición dorios/jonios del principio (Tucídides 5.9.1) no debería haber sido escuchado por los aliados de origen jonio (Hornblower, 2004, II, pp. 442-443).

40 Los klémmata ofurta belli (para los romanos) dan cuenta de las estratagemas utilizadas para engañar al enemigo en la guerra (Gomme, 1956, III, p. 644; Rhodes, 1998, IV, p. 320; Hornblower, 2004, II, p. 444). Esta defensa en boca de Brásidas lo distancia incluso más de los espartanos que eran los principales defensores de la batalla hoplítica convencional (Gomme, 1956, III, p. 644; cf. Tucídides 4.40). Para usos del engaño en general por parte de Brásidas, cf. Tucídides 4.85.7, 108.5, 122.6.

41 Aun así, no se cumple todo lo que dice porque afirma que el ala derecha no soportará el ataque (Tucídides 5.9.4-5), pero en efecto lo hace (Tucídides 5.10.9), cf. Gomme (1954, p. 7).

42 Hornblower (2004) ve este discurso como un "toque efectivo" ya que, al luchar hasta el final, cumplirá con lo que promete hacer. Este no será el último discurso de Brásidas en la obra, sino que habrá uno breve en 5.10.5 (II, p. 441).

43 En este breve comentario nos encontramos de nuevo con la velocidad de respuesta ( $\varepsilon \dot{\theta} \theta \dot{\iota} \varsigma)$, con la persuasión de Cleón ( $\pi \varepsilon เ \sigma \theta \dot{\varepsilon} v \tau \varepsilon \varsigma)$ y con el mismo castigo que había propuesto para Mitilene.

44 Se podría pensar que se trata de un caso más de "sesgo por omisión" al no dar cuenta de los discursos en los que vence (ni siquiera en estilo indirecto), pues solo se refiere el de Mitilene que es precisamente cuando es derrotado, cf. Hornblower (1987, pp. 166-167).

45 Desde una perspectiva histórica, se ha discutido el grado de éxito que tuvo la expedición de Cleón en el Norte. West y Merritt (1925), a los que sigue Woodhead (1960), proponen que la campaña de Cleón en Tracia tuvo un éxito mucho mayor del que Tucídides le reconoce en tanto que en la revaluación de los tributos del 421/0 a.n.e. (A10 = IG $\mathrm{I}^{3} 77$ ) aparece una serie de aldeas, algunas más insignificantes que otras, que no figuran en revaluaciones anteriores. De Romilly (1947, p. 166) y Adcock (1963, p. 248) aceptan esta propuesta, pero consideran que es posible que algunos lugares hayan sido recuperados después de la muerte de Cléon o incluso antes por Nicias. Pritchett (1973), Mitchell (1991) y Spence (1995) discutieron esta tesis en base a cuestiones estratégicas, de ubicación efectiva de los pueblos y de la datación de A10.

46 Gomme (1956) propone que la impaciencia de los soldados se explicaría por el hecho de que Eyón resultaba una base inadecuada y recuerda un pasaje de los Memorabilia (3.5.18-31) en donde Sócrates afirma que los hoplitas y los caballeros son los menos disciplinados de los soldados y se debe posiblemente a la falta de entrenamiento profesional de los strategoi (III, pp. 635, 638). El comentarista, asimismo, cuestiona que la narrativa haya sugerido en algún momento que los atenienses tenían un miedo exagerado por Brásidas o que Cleón haya mostrado alguna falta de inteligencia militar, incluso de malakía pues los primeros ya habían luchado contra el lacedemonio y el segundo había mostrado tener sentido en Pilos al no interferir con el plan de Demóstenes (Gomme, 1956, III, p. 637). A pesar de ello, vimos que Cleón mostró cobardía cuando Nicias le ofreció el mando y no es tanto la falta de experiencia de los soldados con Brásidas, como la del político para guiarlos. Resulta interesante que en Tucídides 4.129.1 es el lacedemonio quien se mantiene en su lugar al ver que no puede recuperar Mende, cf. Westlake (1968, p. 158 n.2).

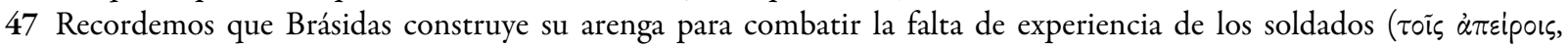
Tucídides 4.126.5), su discurso es una enseñanza para darles más confianza.

48 Cf. Tucídides 2.65.8.

49 Se ha discutido quiénes son la fuente para este relato y la crítica coincide en que posiblemente se trate de los mismos soldados que no aceptaban a Cleón como general (Mitchell, 1991, p. 182; Saldutti, 2014, p. 152). Por otra parte, Woodhead (1960) sostiene que el relato de los hechos de Anfípolis tienen como fuente a "disgruntled hoplites, casting 
back in their memories nineteen or more years later" (p. 308), cf. Pritchett (1973, p. 384) quien no encuentra en A10 ningún elemento para apoyar dicha afirmación.

50 Demóstenes, por su parte, los pone a trabajar cuando estos se sienten intranquilos (Tucídides 4.4.1), pero ningún momento los pone a tiro de sus enemigos.

51 Sobre el discurso de justificación, cf. Charaudeau (2008, pp. 126-127).

$52 \mathrm{El}$ autor resalta el hecho de que ambas campañas son puestas en relación por el mismo enunciador-historiador.

53 Baldwin (1968) es el único que parece haber remarcado el contraste (p. 213) y Nikolaidis (1990) con buen criterio a nuestro entender, resalta que no es lo mismo liderar un ejército que arengar al pueblo (p. 93, n.29).

54 Cf. Gomme (1956, III, p. 638).

55 Recordemos que en Pilos quien dispuso las tropas atenienses en orden fue Demóstenes (Tucídides 4.32.3-4).

56 Anderson (1965) retoma la distinción de Arriano entre órdenes verbales, señales visuales y el uso de la trompeta. Gomme (1956), por su parte, sostiene que Cleón habría ignorado el principio de que el ala derecha debería haber estado ubicada para cubrir el comienzo de la marcha hacia Eyón, pues de haberlo hecho, ni él ni el ala izquierda habrían sido tomados por sorpresa (III, p. 634). El comentarista considera que el hijo de Cleeneto estaba "demasiado impaciente y confiado" en que sabía todo de la situación y que no sería atacado.

57 Gomme (1956) enfatiza este contraste. A pesar de ello, el comentarista indica que Cleón habría esperado el ataque de Cleáridas y no se habría ido con el ala izquierda -la que se desbanda- como correspondía al comandante de la fuerza (III, p. 652). Por otra parte, sostiene que el verbo pheúgein no debe suponer una vergüenza (Gomme, 1954, p. 8). Aun así, creemos que en este pasaje opera para dar cuenta de un comportamiento vergonzoso por parte de Cleón, independientemente de que haya ocurrido así o no.

58 Es verosímil, pues, pensar que la representación de Brásidas, aun con sus defectos, permitiría excusar a Tucídides como general por haber perdido Anfípolis ante un hombre tal (Hornblower, 2004, II, p. 38). 